\section{Reforma na atenção primária à saúde e implicações na cultura organizacional dos Agrupamentos dos Centros de Saúde em Portugal}

\author{
Primary health care reform and implications for the \\ organizational culture of Health Center Groups in \\ Portugal
}

\section{La reforma de la atención primaria de la salud y las implicaciones en la cultura organizacional de los Agrupamientos de los Centros de Salud en Portugal}

\begin{abstract}
The health sector's increasing complexity poses major challenges for administrators. There is considerable consensus on workforce quality as a key determinant of success for any health reform. This study aimed to explore the changes introduced by an action-training intervention in the organizational culture of the 73 executive directors of Health Center Groups (ACES) in Portugal during the primary health care reform. The study covers two periods, before and after the one-year ACES training, during which the data were collected and analyzed. The Competing Values Framework allowed observing that after the ACES action-training intervention, the perceptions of the executive directors regarding their organizational culture were more aligned with the practices and values defended by the primary health care reform. The study highlights the need to continue monitoring results over different time periods to elaborate further conclusions.
\end{abstract}

Health Care Reform; Health Centers; Primary Health Care; Organizational Culture
Claudia Leone 1

Gilles Dussault 1

Luís Velez Lapão ${ }^{1}$

\section{Resumo}

A crescente complexidade dos desafios do setor da saúde implica um aumento das responsabilidades para aqueles que nela assumem funções de gestão. Há consenso que a qualidade da força de trabalho em saúde é um fator crítico para o sucesso de qualquer reforma no setor. O objetivo desta investigação é estudar e analisar a alteração induzida por uma intervenção de formação- ação intensiva na cultura organizacional de 73 diretores executivos dos Agrupamentos dos Centros de Saúde (ACES) em Portugal durante a reforma na atenção primária à saúde. Os dados foram coletados e analisados em dois períodos temporais, antes e depois da intervenção do Programa Avançado em Gestão, Governação Clínica e Liderança para os ACES, o qual teve um ano de duração. O modelo Competing Values Framework permitiu observar que, depois da intervenção de formação-ação, as percepções dos diretores executivos sobre a sua cultura organizacional se encontram mais alinhadas com a reforma da atenção primária à saúde, valorizando o tipo de práticas e valores que esta defende. É necessário continuar a monitorizar os resultados em vários períodos temporais para elaborar conclusões a esse respeito.

Reforma dos Serviços de Saúde; Centros de Saúde; Atenção Primária à Saúde; Cultura Organizacional 


\section{Introdução}

Com intuito de responder às necessidades e desafios do sistema de saúde, o Ministério da Saúde português planejou uma reforma nacional da atenção primária à saúde. A atuação sobre esta se desenvolveu essencialmente em duas fases: na primeira, a partir de 2005, deu-se início à criação das unidades de saúde familiar (USF) - unidade funcional multiprofissional, com autonomia funcional e técnica, com o objetivo de prestar cuidados de saúde primários personalizados (Decreto-Lei no 23/2006 de 2 de fevereiro) - cuja constituição é voluntária (neste momento cobre cerca de $50 \%$ da população); na segunda fase, iniciada em 2009, uma mudança estrutural reagrupou os 347 Centros de Saúde existentes em 73 Agrupamentos dos Centros de Saúde (ACES) 1, o que implicou a eliminação das 14 sub-regiões de saúde 2 . Os ACES abrangem o país todo, cada um cobrindo uma população que varia de 50.000 a 250.000 usuários, aproximando-se da dimensão do Conselho/Município e da referenciação para um hospital.

O sistema de saúde português é um sistema público de Serviço Nacional de Saúde (SNS), muito semelhante ao National Health Service inglês, que cobre toda a população. A atenção primária é o acesso de primeira linha, na qual se incluem os programas de saúde materna e infantil, além da gestão das doenças crônicas. $\mathrm{O}$ acesso aos cuidados secundários (hospitais distritais, centrais e especializados) é feito ou por referenciação da atenção primária (ACES) ou por meio dos serviços de urgência dos hospitais. Existe ainda um serviço de emergência médica nacional (INEM), que, com o apoio de ambulâncias e helicópteros devidamente equipados, dá resposta aos casos mais urgentes.

A segunda fase da reforma revelou, desde o início, um conjunto de problemas próprios do processo de implementação dos novos ACES. Entre eles, estava a ausência de recursos humanos $(\mathrm{RH})$ capacitados nas áreas da gestão e a não atribuição de autonomia financeira a estas novas unidades administrativas ${ }^{3}$. Os ACES são constituídos por um corpo de unidades funcionais responsáveis por prestar serviços de saúde (Unidade de Cuidados na Comunidade, Unidade de Saúde Pública etc.), e as Administrações Regionais de Saúde (ARS) encontram-se, na realidade, a funcionar num cenário novo, o qual tem implicado a adoção de novas tarefas, condições e, sobretudo, de novas competências e atitudes por parte de seus funcionários.

Essa reforma ambiciona promover a implementação de uma nova cultura de trabalho, tendo uma gestão mais próxima e promovendo a governação clínica, que venha contrariar práticas anacrônicas, excessivamente centralizadoras e burocráticas da administração pública. Desde seu início, a reforma enfrentou muita pressão para demonstrar a capacidade de obter resultados positivos rápidos e mensuráveis; no entanto, tinha que enfrentar, ainda, o desconhecimento quanto à forma mais adequada de gerir os processos de mudança apenas com os recursos disponíveis. Um dos aspetos mais polêmicos foi a nomeação, pelas ARS, dos diretores executivos dos ACES, mesmo existindo um conjunto de critérios. A controvérsia surgiu devido ao fato de a maioria dos diretores executivos selecionados serem médicos de carreira, com pouca experiência e formação em gestão. O argumento principal para a escolha desses profissionais foi o conhecimento da realidade e a experiência na atenção primária à saúde.

Em 2008, o Ministério da Saúde avançou com uma iniciativa coordenada pela Missão para os Cuidados de Saúde Primários (MCSP), uma força-tarefa do Ministério da Saúde, a fim de oferecer formação específica aos diretores executivos, direcionada para as funções que iriam ocupar. Essa intervenção foi denominada PACES (Programa Avançado em Gestão, Governação Clínica e Liderança para os ACES), cujo objetivo era contribuir para o processo de mudança organizacional. O desenho da intervenção teve em consideração o Decreto-Lei que previa as atribuições e responsabilidades dos diretores executivos; considerou, também, uma série de premissas em torno da necessidade de uma liderança forte por parte desses profissionais num contexto complexo de mudança 4,5 , de formação 6 focalizada na resolução de problemas concretos 7,8, de métodos para desenvolver competências cognitivas e interpessoais 9,10 , destacando, por fim, a importância de desenvolver redes e parcerias para a partilha das boas práticas de gestão 11,12. A avaliação do impacto da intervenção do programa PACES foi considerada positiva pelos diretores executivos 13 .

Apesar do compromisso implícito de fortalecer a atenção primária à saúde para melhorar a oferta de serviços ao cidadão, em termos gerais, essa dinâmica não tem sido analisada de forma sistemática 14 . Uma vez iniciada a reforma, permanece, ainda, a questão de até que ponto os objetivos iniciais estão indo ao encontro da cultura latente, associada a estruturas e processos não visíveis e inconscientes, e de competências dos profissionais necessárias, para, assim, desencadear a motivação e criatividade para implementar novas práticas de forma sustentável.

A investigação que sustenta o presente estudo inclui também observar o papel dos ACES no 
desenvolvimento da reforma da atenção primária à saúde, os desafios para a gestão dos seus diretores executivos e a necessidade de explorar o conceito de cultura organizacional. Dessa forma, será possível identificar o tipo de cultura latente entre os membros de uma organização e observar a sua evolução e mudanças segundo o pretendido com o PACES, como suporte à definição de uma estratégia para uma implementação de sucesso da reforma da atenção primária à saúde. O presente artigo foca-se neste último aspeto.

\section{Reforma e mudança organizacional em Agrupamentos de Centros de Saúde}

Mintzberg 15 e outros investigadores 16,17 consideram as organizações de saúde as mais complexas, pela diversidade dos seus serviços, variedade de profissionais com competências distintas, vários processos ocorrendo simultaneamente $\mathrm{e}$ pela necessidade de uma abordagem holística. Em um processo de reforma, a complexidade aumenta, pois o sistema precisa de se adaptar às novas forças intrínsecas à mudança, ao mesmo tempo em que procura diferentes soluções para responder às mais recentes exigências da saúde $18,19,20,21$.

Biscaia et al. 22 e Lapão 5, referindo-se especificamente às organizações envolvidas no processo de reforma da atenção primária à saúde em Portugal, reiteram que, considerando as características complexas do sistema, essas organizações são um benefício, por se tratarem de estruturas flexíveis para melhor tirar partido da incerteza e da necessidade de rápidos reajustamentos. Os profissionais dessas organizações da saúde deveriam se comportar como agentes individuais, interligados com os demais, mas com liberdade para agir e inovar. Tais considerações valorizam o interesse no desempenho dos $\mathrm{RH}$.

Existe um consenso na literatura de que o comportamento dos $\mathrm{RH}$ representa um componente crítico para a implementação de novos paradigmas de gestão nos serviços de saúde, em especial na área pública 23,24. O desempenho de qualquer organização depende, sobretudo, da força de trabalho, e uma má administração explica, em boa parte, os fracos resultados dos serviços de saúde. As suas consequências são piores ainda nos sistemas de saúde que dedicam poucos recursos a esse tipo de serviço 18,25.

Contudo, o desenvolvimento dos $\mathrm{RH}$ e das lideranças, o enfoque na motivação e na identificação dos gestores da saúde é preocupação recente. Apesar de o desenvolvimento de lideranças ser reconhecido há vários anos como um instrumento fundamental para acompanhar os novos desafios e as necessidades de saúde da população, não tem sido suficientemente explorado e implementado 20 . Os métodos para o seu desenvolvimento são também ainda vagos e carregados de dificuldades 26 .

Para melhorar o desempenho, uma intervenção do tipo formação em gestão pode ser desenvolvida de várias formas, entre elas, workshops, sessões teóricas e práticas, simulações, trabalhos de campo ou uma combinação dessas estratégias 27.

Mas a aquisição de competências por meio de programas de formação não torna um gestor necessariamente competente 8 . As organizações, em sua maioria, limitam-se a "enviar os seus colaboradores para programas de desenvolvimento de competências de modo a receber logo de volta gestores mais desenvolvidos" 8 (p. 342). Ensinar conceitos pode ser relativamente simples, mas desenvolver competências e saber aplicá-las de forma correta não é tarefa fácil 8,28,29, principalmente porque o que é aprendido deve ser enquadrado no contexto de atuação 28.

Os gestores em formação não devem ser vistos unicamente como recipientes de informação; deve considerar-se que são "participantes de um processo de aprendizagem” 8 (p. 317). Portanto, a lógica da formação não pode se basear unicamente na participação das pessoas nesses tipos de curso 8,25 . Não se trata só de oferecer ferramentas e técnicas para que os profissionais façam uso delas e possam desempenhar as suas tarefas; a importância da disposição para aceitar mudanças, atitudes e valores dos próprios profissionais é um fator-chave para potencializar o tempo na formação. De fato, um dos desafios mais evidentes no contexto de uma reforma é conseguir o mais rapidamente possível a adesão dos profissionais da saúde a ela 30,31. A dificuldade dessa adesão levanta uma série de questões que vão ser tratadas a seguir.

Mudar atitudes e comportamentos pode resultar numa das tarefas mais difíceis de realizar 32. As atitudes e os comportamentos dependem, em grande parte, do contexto da situação, da natureza e extensão do processo de mudança e da forma como este foi iniciado ou implementado. Pode subsistir intolerância à mudança que iniba o processo antes mesmo que as pessoas se apercebam da sua importância e benefícios 31 . Iniciativas de mudança que evitam compreender e gerir a cultura existente, antes de tentar mudar para uma nova cultura, tendem a falhar 33,34,35. Dessa forma, a compreensão e a análise da cultura organizacional permitem que se desenvolvam estratégias para manter a coesão dos componentes de uma organização; por outro lado, fomentam a continuidade e consistência nas organi- 
zações mediante a adesão dos seus membros a uma série de novos valores consensuais 33 .

A gestão da cultura organizacional vem sendo vista como cada vez mais necessária no contexto de uma reforma de saúde 36. Existe alguma evidência que sugere que a cultura organizacional pode ser um fator relevante no desempenho de organizações na saúde 36,37,38. Vários autores 33,39 foram desenvolvendo um modelo teórico denominado Competing Values Framework (CVF), por meio do qual foi criada uma ferramenta qualitativa, the Organization Culture Assessment Instrument (OCAI), a qual permite compreender e interpretar melhor a cultura organizacional. O CVF, junto com o OCAI, vem sendo aplicado em vários tipos de organizações $33,39,40,41$, entre elas organizações de saúde 37,38,42,43,44, para se obter um diagnóstico sobre quão forte são percebidos os valores pelos membros de uma organização e com que tipos de cultura se identificam.

\section{The Competing Values Framework}

O CVF conceptualiza as diferenças entre culturas organizacionais considerando duas dimensões: a estrutura, ou relação na qual se baseiam os processos, e o foco. A dimensão da estrutura varia entre flexibilidade, num extremo, e controle, no extremo oposto. Essa dimensão captura as diferenças entre as organizações que tendem a manter padrões consistentes no tempo e aquelas que permitem aos seus colaboradores ditar os seus próprios comportamentos 39 , refletindo a forma como são gerenciados os processos dentro de uma organização. A dimensão do foco descreve a orientação da organização em face do mundo exterior e varia entre foco externo e foco interno. Este último salienta questões tais como a satisfação dos trabalhadores em contraste com o foco externo, que destaca aspectos relacionados com a habilidade da organização de funcionar no seu ambiente ou contexto 39 .

Tendo essas dimensões como base, o CVF classifica as organizações segundo uma tipologia composta por quatro espécies de cultura organizacional: de clã, de mercado ou racional, hierárquica e adocrática ou de desenvolvimento. Cria, assim, um modelo de quatro quadrantes (Figura 1), no qual se encontram refletidos os indicadores de efetividade organizacional que estão associados a cada uma dessas culturas.

O quadrante inferior esquerdo representa a cultura hierárquica, tendo como base o modelo de Weber 45 sobre os atributos clássicos da burocracia. Esta cultura se caracteriza como um espaço de trabalho muito formal e estruturado, no qual os procedimentos regem o que as pessoas fazem. São as regras formais e as políticas que mantêm a organização coesa. A longo prazo, a preocupação é a estabilidade, o desempenho harmônico e eficiente.

O quadrante inferior direito caracteriza a cultura de mercado. Trata-se de uma tipologia de

Figura 1

Competing Values Framework (CVF): modelo de valores concorrentes.

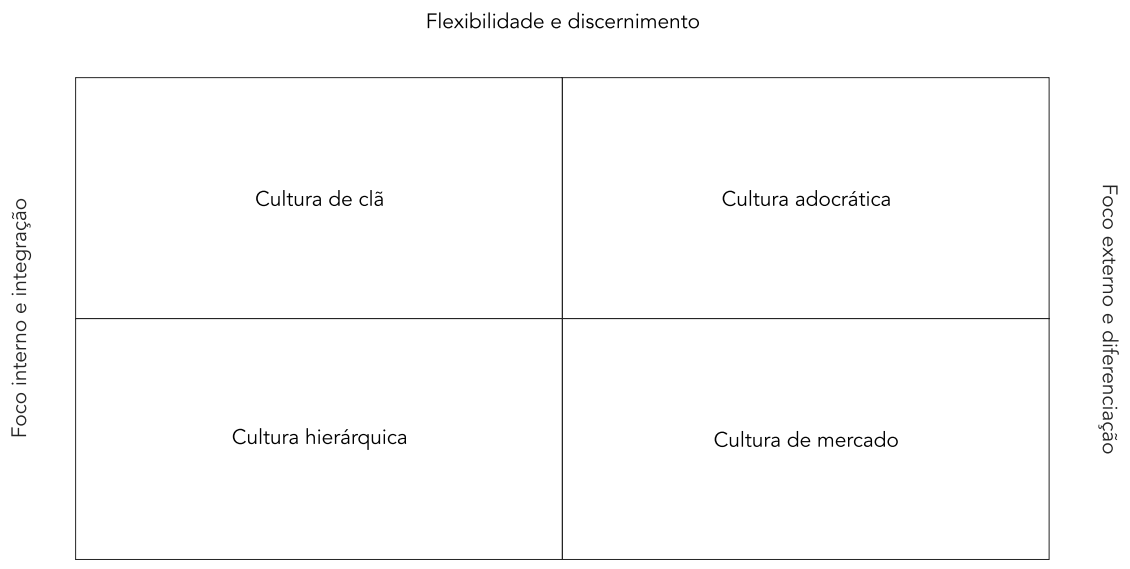

Estabilidade e controle 
organização orientada para o ambiente externo (clientes, fornecedores, licenças etc.), em detrimento dos assuntos internos. O principal objetivo é orientar a organização na direção da produtividade, de resultados e do lucro, criando vantagem competitiva, que pode ser atingida por intermédio do melhor posicionamento externo. Na linha do OCAI, este tipo de cultura se define como um espaço de trabalho orientado para os resultados. Essas duas primeiras culturas se encontram no mesmo extremo da dimensão da estrutura; nesse tipo de organização, a estabilidade, a ordem e o controle são características valorizadas.

Em relação à dimensão do foco, a cultura hierárquica se situa no foco interno, enquanto a do mercado, no foco externo, visto que o seu objetivo é salientar aspectos como a concorrência e a diferenciação.

A cultura de clã, que se encontra no quadrante superior esquerdo, representa a flexibilidade, discernimento e foco interno, definindo-se pela sua similaridade com um tipo de organização familiar. Em vez de regras e procedimentos próprios das hierarquias, além de foco no lucro e na concorrência como na cultura de mercado, este tipo de organização se baseia em trabalho de equipe, programas de envolvimento do pessoal e de compromisso com os seus trabalhadores; mantém-se coesa pela sua tradição e fiabilidade, criando laços de compromisso entre as pessoas. A organização tende a premiar o trabalho em grupo e o consenso.

Finalmente, o quadrante superior direito identifica a cultura adocrática, que representa a flexibilidade, o discernimento e a diferenciação. Aspectos como a inovação e iniciativas pioneiras são considerados como os pontos que levam ao sucesso. Mintzberg 7 se refere à adocracia como um tipo de organização que é oposta à burocracia, sendo caracterizada pela maior abertura à inovação, com baixo nível de formalização, distanciando-se dos padrões tradicionais estabelecidos. A cultura adocrática é compreendida como um espaço de trabalho dinâmico, empreendedor e criativo. Os membros deste tipo de organização tendem a aceitar riscos e a aderir a processos de inovação.

Esses dois últimos tipos de culturas organizacionais, ao se posicionarem nos extremos superiores do quadrante, situam-se no extremo de flexibilidade e espontaneidade na dimensão da estrutura. A cultura de clã na dimensão do foco se situa no extremo do foco interno, visto que valora aspectos relacionados com o trabalho em equipe, enquanto a cultura adocrática se situa no extremo oposto da mesma dimensão, sendo seu objetivo inovar e tomar riscos para se diferenciar e evoluir.
Com base nestas dimensões e tipologias, o CVF permite identificar a cultura organizacional mais dominante dentro de uma organização, assim como sua força e sua congruência, ou coerência. Em relação ao primeiro aspecto, a força da cultura organizacional é determinada pelo número de pontos que cada uma das culturas tem; quanto maior for a pontuação, mais dominante ela é. As culturas fortes estão associadas a uma homogeneidade de esforços entre os membros da organização e a um melhor desempenho em ambientes nos quais é requisito ter visão partilhada ${ }^{33}$. Na cultura organizacional, a coerência acontece quando várias de suas dimensões estão alinhadas. As culturas coerentes tendem a ter um melhor desempenho que as culturas que não são coerentes. Ter todos os aspectos de uma organização focados nos mesmos valores elimina muitas complicações e obstáculos no caminho para um desempenho eficiente 33 . A presença da "incoerência" cultural frequentemente resulta num estímulo à mudança, pois se observa um desconforto e ambiguidade, assim como a falta de integração entre os seus membros.

\section{Metodologia}

A presente investigação descreve as mudanças de percepção dos dirigentes dos ACES sobre a cultura organizacional no âmbito da reforma da atenção primária à saúde, antes e depois de uma intervenção de formação-ação (PACES). Essa iniciativa foi desenhada especificamente para os profissionais nomeados para desempenhar a função de diretores executivos dos ACES em parceria com o Ministério de Saúde. O PACES esteve em curso durante um ano, coincidindo com todo o primeiro ano da função dos novos diretores executivos. O seu início em 2008 e o seu fim em 2009 representam os dois períodos temporais durante os quais foram recolhidos os dados que serão analisados a seguir.

A duração total do programa foi de 400 horas, das quais 280 horas corresponderam a horas de trabalhos presenciais; 60 horas, a tutoriais organizados em pequenos grupos de cinco a sete pessoas; e as restantes 60 horas foram usadas em eLearning e discussões sobre temas tais como complexidade e gestão da mudança, desenvolvimento de recursos humanos, entre outras ${ }^{3}$. Esse programa correspondeu a uma sessão de oito horas de trabalho semanal. A formação contemplou sete módulos, dos quais se destacam complexidade e liderança para a gestão da mudança, logística e gestão da inovação e governação clínica. As sessões presenciais ocorreram em três regiões 
de Portugal: Porto (norte), Coimbra (centro) e Lisboa (sul).

Esta investigação pretende continuar repetindo a aplicação desta metodologia em vários períodos da função dos diretores executivos, para obter um melhor diagnóstico da influência da intervenção de formação na sua cultura organizacional ao longo do tempo. No entanto, o tempo decorrido entre a primeira e segunda coleta de dados permite observar mudanças nas percepções dos profissionais selecionados para desempenhar uma nova função numa nova estrutura administrativa, marcando o tom para as futuras intervenções.

A metodologia empregada para o recolhimento de dados foi um questionário, aplicado a todos os diretores executivos, considerando uma amostra censitária em dois períodos diferentes. No primeiro momento, obtiveram-se respostas de 64 participantes, num total de 73 diretores executivos (taxa de resposta $87,7 \%$ ); no segundo momento, 62 participantes preencheram os questionários devidamente (taxa de resposta $85 \%$ ).

Os diretores executivos participantes do estudo são majoritariamente homens $(58,5 \%$ dos que responderam no primeiro questionário e $56,5 \%$, no segundo), de idade igual ou superior a 50 anos ( $87,5 \%$ e 90,3\% respectivamente) e médicos de carreira (82,8\% e $79 \%$ respectivamente). As demais profissões declaradas foram gestores ou administradores hospitalares (6,3\% e 11,3\%) e outras (10,9\% e 9,7\%).

O questionário aplicado compõe-se de perguntas sociodemográficas e de perguntas pertencentes à ferramenta OCAI 33, a qual conta com seis itens ou categorias: (1) características dominantes da organização; (2) estilo de liderança presente na organização; (3) estilo de gestão e de relacionamento com os colaboradores e ambiente de trabalho resultante; (4) aspetos que mantêm a organização coesa e unida; (5) foco estratégico que define as linhas de ação da organização para o futuro; (6) critérios que determinam o sucesso, tornando-o merecedor de ser recompensado. Cada uma dessas categorias apresenta quatro opções de resposta, representando os quatro tipos de cultura organizacional já mencionados.

No presente estudo, para facilitar o processo de resposta, em vez de se pedir aos inquiridos que distribuíssem 100 pontos entre as quatro alternativas de cada item de pergunta ou categoria, como é indicado pelos autores desta ferramenta, foi solicitado que selecionassem uma única opção de resposta, com a qual se identificassem mais. Apesar de ser uma alteração no sistema de pontuações da própria ferramenta, não interfe- riu no objetivo da identificação da cultura organizacional percebida como mais dominante por parte dos inquiridos.

\section{Resultados}

Nos dados de 2008, antes da intervenção PACES, a cultura organizacional observada como dominante entre os diretores executivos foi a cultura de clã, com uma pontuação média de 34,1 (Tabela 1). Nos dados de 2009, a cultura de clã continuou a ser percebida como dominante, mas com uma pontuação média de 40,8 pontos relativamente à de 2008 (Tabela 1). O aumento de pontuação relacionou-se com o aumento da força da cultura percebida, significando que os valores próprios desse tipo de cultura se encontravam ainda mais presentes na organização que há um ano antes.

Em relação à coerência da cultura organizacional nos ACES, observa-se que, em 2008, as pontuações mais altas se encontravam divididas entre três tipos de cultura (de clã, adocrática e hierárquica). No segundo período temporal, as pontuações se concentraram mais nas duas culturas dos quadrantes superiores do modelo - clã e adocrática (Figura 2). Em 2008, as pontuações encontravam-se mais espalhadas entre essas três culturas, sendo maior a coerência da cultura organizacional dos ACES em 2009.

Continuando-se a observar as pontuações, verificam-se mudanças claras na cultura com a segunda pontuação mais alta (efeito de segunda ordem). Em 2008, a cultura hierárquica mantinha uma pontuação de 27,1, que a colocava como segunda cultura dominante, só sete pontos abaixo da cultura de clã. Um ano mais tarde, a cultura hierárquica se reduziu à metade, sendo substituída pela cultura adocrática como a segunda cultura mais dominante, com uma pontuação que ultrapassou a da cultura hierárquica no primeiro período temporal. Esse resultado demonstra um realinhamento das duas dimensões do CVF. No primeiro período, sendo as culturas de clã e a hierárquica as mais dominantes, a dimensão mais representada pelas percepções dos diretores executivos era a do foco no extremo do foco interno, no qual se valorizam aspectos como a integração e a satisfação das equipes. No segundo período, a dimensão dominante passou a ser a dimensão das relações, nas quais de baseiam os processos no extremo da flexibilidade, em contraste com o controle e estabilidade (Figura 2).

Numa análise individual, pode-se observar que as seis categorias mantêm a mesma cultura organizacional dominante em ambos os períodos (Tabela 2). A maioria delas se encontra 
Somatório das porcentagens das culturas, segundo o modelo OCAI (Organization Culture Assessment Instrument).

\begin{tabular}{lccc}
\hline Respostas/Culturas & $\begin{array}{c}\text { Primeiro questionário (2008) } \\
\text { Somatório (porcentagem } \\
\text { válida/6 categorias) }\end{array}$ & $\begin{array}{c}\text { Segundo questionário (2009) } \\
\text { Somatório (porcentagem } \\
\text { válida/6 categorias) }\end{array}$ & $\begin{array}{c}\text { Diferenças proporcionais } \\
\text { (2009-2008) }\end{array}$ \\
\hline A - Clã & 34,1 & 40,8 & $+6,7$ \\
B - Adocrática & 23,6 & 29,0 & $+5,4$ \\
C - Mercado & 12,3 & 12,1 & $-0,2$ \\
D - Hierárquica & 27,1 & 13,9 & -13.2 \\
\hline
\end{tabular}

Figura 2

Resultados da cultura organizacional em 2008 e 2009.

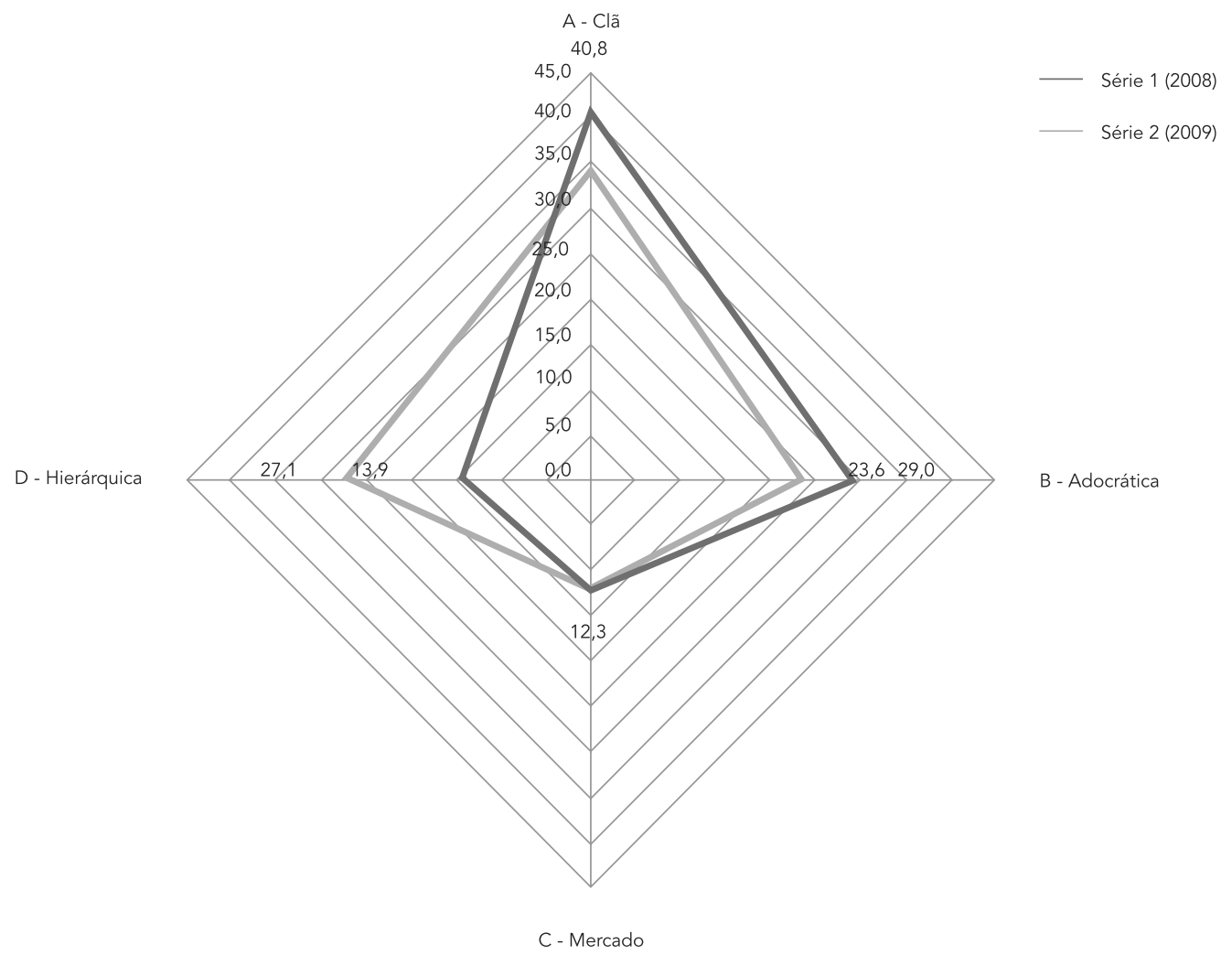

identificada com a cultura de clã (estilo de gestão, fatores de coesão e critérios de sucesso) e com a cultura adocrática (características dominantes e estratégia para o futuro). A categoria de liderança organizacional é a única que pertence a uma cultura hierárquica em ambos os períodos, tendo, inclusive, maior pontuação em 2009.

O item liderança organizacional permite perceber como o gestor de uma organização lidera os seus colaboradores para cumprir os objetivos 
Somatório das porcentagens por categorias, segundo o modelo OCAI (Organization Culture Assessment Instrument).

\begin{tabular}{|c|c|c|c|c|c|c|c|c|}
\hline \multirow[t]{2}{*}{ Categorias } & \multicolumn{4}{|c|}{$\begin{array}{c}\text { Primeiro questionário (2008) } \\
\text { Somatório (porcentagem } \\
\text { válida/6 categorias) }\end{array}$} & \multicolumn{4}{|c|}{$\begin{array}{c}\text { Segundo questionário (2009) } \\
\text { Somatório (porcentagem } \\
\text { válida/6 categorias) }\end{array}$} \\
\hline & A & B & C & $D$ & A & B & C & D \\
\hline Características dominantes & 7,7 & 38,5 & 21,5 & 27,7 & 11,3 & 43,5 & 29,0 & 12,9 \\
\hline Liderança organizacional & 33,8 & 15,4 & 7,7 & 36,9 & 19,4 & 24,2 & 6,5 & 40,3 \\
\hline Estilo de gestão & 53,8 & 6,2 & 12,3 & 24,6 & 71,0 & 11,3 & 9,7 & 6,5 \\
\hline Fatores de coesão & 35,4 & 18,5 & 12,3 & 32,3 & 43,5 & 29,0 & 19,4 & 6,5 \\
\hline Estratégia para o futuro & 26,2 & 43,1 & 16,9 & 12,3 & 38,7 & 48,4 & 8,1 & 1,6 \\
\hline Critérios de sucesso & 47,7 & 16,9 & 3,1 & 29,2 & 61,3 & 17,7 & 3,2 & 16,1 \\
\hline $\begin{array}{l}\text { Total pontuação (cultura organizacional/ } \\
6 \text { categorias do modelo) }\end{array}$ & 34,10 & 23,60 & $12 ., 30$ & 27,16 & 40,86 & 29,01 & 12,11 & 13,98 \\
\hline
\end{tabular}

da organização 33. Quando esta dimensão posiciona-se sobre a cultura hierárquica, significa que o gestor desempenha a sua função como um administrador da organização, em contraste com a função de mentor ou de inovador, aceitando correr riscos. A sua gestão é feita mediante normas estruturadas e formais para manter o controle da informação, privilegiando a documentação e gestão de informação. Neste tipo de organização, a definição de objetivos claros e a autoridade no processo de tomada de decisões são fundamentais.

\section{Discussão}

As mudanças organizacionais percebidas como necessárias no sistema de saúde português implicam um conjunto de novas estratégias, contrariando décadas de funcionamento de uma administração pública com tendência centralista. Levando-se em conta que esses processos requerem algum tempo, apoios externos e internos, recursos e ainda uma seleção adequada dos RH 18,46,47, pretende-se a transição de uma velha lógica de funcionamento hierárquico e vertical, para uma dinâmica alicerçada na contratualização e em redes de serviços partilhados 46 . Nesse contexto, caracterizado por bastante incerteza quanto à evolução da economia, fundamenta-se o valor e importância da força de trabalho em saúde para a sustentabilidade de qualquer tipo de reforma ${ }^{48}$, pois dela depende o desempenho de qualquer organização 25 . Essa observação valida a importância das políticas de RH na saúde e as medidas concretas de gestão, entre elas a liderança, a criação de condições necessárias e a motivação do pessoal de saúde com os meios para aprenderem e se adaptarem, evoluindo para perspectivas orientadas para o doente 47 .

O estudo realizado confirma que a cultura tipo clã é a cultura organizacional que domina entre os ACES. Organizações com esse tipo de cultura mantêm-se coesas devido à lealdade e à tradição entre os seus membros. O sucesso é definido em termos de ambiente interno e preocupação pelas pessoas 1. De acordo com Gregory et al. 44 , a cultura de clã, ou cultura de grupo, tende a ter influência positiva nas organizações, mas mais particularmente nas organizações relacionadas com a saúde. A própria natureza das organizações da saúde requer empatia, além do desenvolvimento de algum tipo de relação de proximidade entre os fornecedores de saúde e os cidadãos ${ }^{49}$. A sua razão de ser baseia-se na melhoria da saúde da população que servem; logo, a fim de oferecer serviços de saúde com qualidade, os membros de uma organização de saúde precisam trabalhar em equipes e criar um sentido de trabalho em grupo.

Ao mesmo tempo, esses resultados permitiram observar que, após o PACES, as percepções dos diretores executivos sofreram algumas mudanças em relação ao ano anterior. Apesar de a cultura mais dominante em 2009 continuar sendo a mesma que em 2008, a do segundo momento demonstrou mudanças significativas. Passouse de uma organização com uma forte pontuação na tipologia hierárquica a uma organização que ganhou pontuação numa tipologia adocrática, a qual apresenta melhores características para se adaptar e enfrentar riscos em face de uma situação de mudança. Uma cultura organizacional, na qual dominam as culturas de clã e adocrática 
encontra-se em linha com os objetivos iniciais da intervenção de formação-ação PACES. Por isso, considera-se que, comparativamente ao primeiro ano, as percepções dos diretores executivos estão alinhadas, valorizando o tipo de práticas, presunções e valores que a reforma da atenção primária à saúde defende.

No entanto, o resultado observado na análise individual, relativo à categoria de liderança organizacional, levanta algumas questões. Nesta categoria, o tipo de liderança hierárquica tende a funcionar em contextos nos quais a experiência e o conhecimento de quem lidera são maiores do que os dos colaboradores; contextos em que a confiança no desempenho da equipe ainda não se encontra muito desenvolvida. Trata-se de uma liderança formal que tende a não motivar o trabalho em equipe. Portanto, esse resultado pode significar que, perante uma mudança organizacional que valoriza a flexibilidade (aumento da adocracia), persiste ainda a perspectiva da necessidade de uma liderança que se impõe, sobretudo, quando decisões precisam ser tomadas.

Num processo de reforma, mudar e realinhar atitudes e comportamentos já estabelecidos é uma tarefa muito difícil 34,50 , e o período entre a primeira e a segunda coleta de dados pode não ter sido suficiente para emitir conclusões que permitam melhor compreensão das mudanças na cultura organizacional dos diretores executivos. Contudo, pode-se considerar que os desafios próprios de um processo de mudança, o objetivo de horizontalizar uma estrutura com uma larga tradição centralista, vertical e hierárquica na atenção primária à saúde, conjuntamente com a falta de autonomia financeira das novas unidades de saúde, podem estar contribuindo para esse tipo de lideranças e ambientes laborais, nos quais a confiança no desempenho na equipe ainda não se encontra instaurada 14 .

\section{Conclusões}

Uma organização é mais que a soma das suas partes, e uma reforma da atenção primária à saúde é muito mais que uma mera reforma institucional. Um melhor entendimento da cultura organizacional e daqueles que se encontram na primeira linha de uma reforma ajuda a identificar os desafios menos explícitos que vão surgindo no processo. Da mesma forma, é possível observar o grau de sintonia entre, de um lado, a cultura latente ou presente dos membros e, de outro, a cultura organizacional desejável numa organização. Iluminam-se, assim, os aspetos a melhorar e a possível influência de estratégias de formação dirigidas aos seus membros.
Como a presente investigação se refere a uma intervenção em um programa de formação em gestão e liderança, os aspectos analisados estão unicamente associados a fatores que podem ser medidos através dos dados disponíveis. Reconhece-se que possivelmente existam muitos outros fatores a interferir no desempenho dos diretores executivos num contexto de reforma. Os resultados e as conclusões deste estudo limitam-se às percepções de tais profissionais sobre a sua cultura organizacional antes e depois do programa PACES, levando-se em conta que o período temporal de um ano entre coletas de dados só permite identificar tendências e realizar observações.

Relativamente ao questionário, como não se identificaram os participantes em nenhum dos dois momentos de recolhimento de dados, as respostas não podem ser emparelhadas, limitando outras possibilidades de análise estatística. Por fim, considerando o modelo de intervenção preconizado, não foi possível contar com um grupo de controle que permitisse comparar os resultados.

Apesar dessas limitações, o presente estudo representa uma primeira aproximação para compreender as mudanças culturais que ocorrem em contexto de uma reforma da atenção primária à saúde. De forma mais específica, permite compreender o papel das dinâmicas culturais no funcionamento e na sustentabilidade dos ACES como uma organização que se encontra perante desafios significativos.

O estudo das percepções dos diretores executivos dos ACES sobre a sua cultura organizacional num contexto de reforma permite identificar algumas tendências de mudanças positivas após a intervenção PACES, em especial quando se observa a segunda cultura mais dominante. Depois do primeiro ano, as percepções dos diretores executivos no seu conjunto sobre a sua cultura organizacional se encontram mais em sintonia com a reforma da atenção primária à saúde do que em 2008, de modo que eles podem ajudar na implementação das mudanças pretendidas. $\mathrm{O}$ tempo e recursos inseridos no processo também podem ter uma maior influência no funcionamento dos ACES.

Finalmente, reconhece-se que o uso de intervenções, como programas de formação, não é suficiente se não existir, em paralelo, apoio e acompanhamento institucional; a posteriori, é importante a monitorização dos valores expressos dos seus membros e dos pretendidos numa reforma. Este estudo não conclui que a formação PACES teve influência positiva ou definitiva na percepção da cultura organizacional dos diretores executivos, mas assinala que foram obser- 
vadas tendências indicativas de que os valores desejados pela reforma da atenção primária à saúde se encontram presentes nas percepções dos diretores executivos dos ACES. Considera-se necessário continuar a monitorizar os resultados em vários períodos temporais para elaborar conclusões nesse sentido.

\section{Resumen}

La creciente complejidad de los desafíos del sector de la salud implica un aumento de las responsabilidades para quienes asumen funciones de gestión. Existe consenso en que la calidad de la fuerza de trabajo en la salud es un factor crítico para el éxito de cualquier reforma en la salud. El objetivo de esta investigación es estudiar y analizar las alteraciones introducidas por una intervención de formación-acción intensiva en la cultura organizacional de 74 directores ejecutivos de los Agrupamientos de Centros de Salud (ACES) en Portugal, durante la reforma de la atención primaria de la salud. Fueron recogidos y analizados datos en dos periodos temporales, antes y después de la intervención de Programa Avanzado en Gestión, Gobernanza Clínica y Liderazgo para los ACES, que tuvo la duración de un año. El modelo Competing Values Framework permitió observar que, después de la intervención de formaciónacción, las percepciones de los directores ejecutivos sobre su cultura organizacional se encuentran más alineadas con la reforma de la atención primaria de la salud, valorizando el tipo de prácticas y valores que esta defiende. Es necesario continuar supervisando los resultados en varios períodos.

Reforma de La Atención de Salud; Centros de Salud; Atención Primaria de Salud; Cultura Organizacional

\section{Colaboradores}

C. Leone participou do desenho do estudo, coleta e análise de dados e redação do artigo. G. Dussault trabalhou na redação do artigo. L. V. Lapão auxiliou no desenho do estudo, coleta, análise de dados e redação do artigo.

\section{Agradecimentos}

Agradecemos ao AGO (Associação para o Desenvolvimento e Cooperação García da Orta), que deu todo o suporte para a condução da pesquisa. Agradecemos também aos profissionais de saúde que participaram do estudo. 


\section{Referências}

1. Direcção-Geral da Saúde. Centros de saúde e hospitais: recursos e produção do SNS 2006. Estatísticas. Lisboa: Direcção-Geral da Saúde; 2007.

2. Lisboa. Decreto-Lei no $28 / 2008$ de 2 de fevereiro. Diário da República 2008; 22 fev.

3. Lapão LV, Dussault G. PACES: a national leadership program in support of primary-care reform in Portugal. Leadersh Health Serv 2011; 24:295-307.

4. Plsek P, Wilson T. Complexity, leadership, and management in healthcare organisations. BMJ 2001; 323:746-9.

5. Lapão LV. Programa avançado de gestão para directores executivos dos ACES. Lisboa: Instituto Nacional de Administração; 2009

6. Lapão LV. The role of complexity dynamics in the innovation process within the new primary-care governance model in Portugal. Innov J 2008; 13: 1-12.

7. Mintzberg H. Mintzberg on management: inside our strange world of organizations. New York: Free Press/Collier MacMillan; 1989.

8. Mintzberg H. Managers not MBAs: um olhar crítico sobre a gestão. Lisboa: Dom Quixote; 2005.

9. Arthur-Kelly M, Gordon C, Butterfield N. The impact of curriculum and instruction. In: ArthurKelly M, editor. Classroom management: creating positive learning environments. South Melbourne: Thomson; 2003. p. 43-52.

10. Alimo-Metcalf B, Alban-Metcalfe J. Leadership: time for a new direction? Leadership 2005; 1:51-71.

11. Hamel G. The why, what, and how of management innovation. Harv Bus Rev 2006; 84:72-84.

12. Dyer JH, Nobeoka K. Creating and managing a high-performance knowledge-sharing network: the Toyota case. Strategic Management Journal 2000; 21:345-67.

13. Lapão LV, Dussault G. From policy to reality: clinical managers' views of the organizational challenges of primary care reform in Portugal. Int J Health Plann Manage 2012; 27:295-307.

14. Dussault G, Fronteira I. Recursos humanos para saúde: plano integrado no Plano Nacional de Saúde 2011-2016. Lisboa: Alto Comissariado da Saúde; 2010 .

15. Mintzberg $\mathrm{H}$. The structuring of organizations: a synthesis of the research. Englewood Cliffs: Prentice-Hall; 1979.

16. Mick SM, Wyttenbach M. Advances in health care organization theory. San Francisco: Jossey-Bass; 2003.

17. Ruth A, Reuben Jr. R. Managing health care organizations: where professionalism meets complexity science. Health Care Manage Rev 2000; 25:83-92.

18. World Health Organization. World Health Report: working together for health. Geneva: World Health Organization; 2006.

19. Biscaia A. A reforma dos cuidados de saúde primários e a reforma do pensamento. Revista Portuguesa de Clínica Geral 2006; 22:67-79.

20. Dickson G. Transformations in Canadian health systems leadership: an analytical perspective. Leadersh Health Serv 2009; 22:292-305.
21. Wright KL, Rowitz A, MerkleWM, Reid G, Robinson B, Herzog D, et al. Competency development in public health leadership. Am J Public Health 2000; 90:1202-7.

22. Biscaia A, Nunes MJ, Carreira MF, Fronteira IG, Antunes AR, Ferrinho P. Cuidados de saúde primários em Portugal: reformar para novos sucessos. Lisboa: Padrões Culturais Editora; 2006.

23. Dussault G. A gestão dos serviços públicos de saúde: características e exigências. Rev Adm Pública 1992; 26:8-19.

24. Santana JP. A gestão do trabalho nos estabelecimentos de saúde: elementos para uma proposta. In: Santana JP, organizador. Perspectivas para a gestão do trabalho no Sistema Único de Saúde. Brasília: Organização Pan-Americana da Saúde 1994. (Série Desenvolvimento de Recursos Humanos, 5).

25. Dussault G. Gestão dos recursos humanos e qualidade dos serviços de saúde. Educ Méd Salud 1994 28:478-89.

26. Alimo-Metcalfe B, Lawler J. Leadership development in UK companies at the beginning of the twenty-first century: lessons for the NHS? J Manag Med 2001; 15:387-404.

27. Leadership Development National Excellence Collaborative. Collaborative leadership and health: a review of the literature. Seattle: Turning Point Initiative; 2004.

28. Kolb D, Lublin S, Spoth J, Baker R. Strategic management development: using experiential learning theory to assess and develop managerial competencies. Journal of Management Development 1986; 5:13-24.

29. Cunliffe A. On becoming a critically reflexive practitioner. Journal of Management Education 2004; 28:407-26.

30. Biscaia A. A reforma do pensamento em saúde. Revista Portuguesa de Clínica Geral 2006; 22:63-4.

31. Kotter J, Schlesinger L. Choosing strategies for change. Harv Bus Rev 2008; 86:130-8.

32. Robbins SP. Organizational behaviour. 12th Ed. Englewood Cliffs: Prentice-Hall; 1996.

33. Cameron KS, Quinn RE. Diagnosing and changing organizational culture: based on the competing values framework. San Francisco: Jossey-Bass; 2006.

34. Whiteley A. Managing change: a core values approach. South Melbourne: MacMillan Education Australia Pty Ltd.; 1995.

35. Schein E. On dialogue, culture, and organizational learning. Organ Dyn 1993; 21:40-51.

36. Scott T, Mannion R, Marshall M, Davies H. Does organisational culture influence health care performance? J Health Serv Res Policy 2003; 8:105-17.

37. Hann M, Bower P, Campbell S, Marshall M, Reeves D. The association between culture, climate and quality of care in primary health care teams. Fam Pract 2007; 24:323-9. 
38. Marshall M, Mannion R, Nelson E, Davis H. Managing change in the culture of general practice: qualitative case studies in primary care trusts. BMJ 2003; 327:599.

39. Quinn R, Rohrbaugh J. A competing values approach to organizational effectiveness. Public Productivity Review 1981; 5:122-40.

40. Berrio A. An organizational culture assessment using the competing values framework: a profile of Ohio State University Extension. Journal of Extension 2003; 41(2). http://www.joe.org/ joe/2003april/a3.php.

41. Goodman E, Zammuto R, Gifford B. The Competing Values Framework: understanding the impact of organisational culture on the quality of work life. Organization Development Journal 2001; 19:58-68.

42. Wakefield B, Blegen M, Uden-Holman T, Vaughn T, Chrischilles E, Wakefield D. Organisational culture, continuous quality improvement and medication administration error reporting. Am J Med Qual 2001; 16:128-34.

43. Shortell S, O'Brien J, Carman J, Foster RW, Hughes $\mathrm{EF}$, Boerstler $\mathrm{H}$, et al. Assessing the impact of continuous quality improvement/total quality management: concept versus implementation. Health Serv Res 1995; 30:377-401.
44. Gregory B, Harris S, Armenakis A, Shook C. Organizational culture and effectiveness: a study of values, attitudes, and organizational outcomes. J Bus Res 2009; 62:673-9.

45. Weber M. The theory of social and economic organization. New York: The Free Press; 1947.

46. Frias V. Entrevista a Luís Pisco, coordenador da MCSP. Até ao verão, os ACES têm que estar criados. http://www.jmfamilia.com/index.php?option= com_content \&task=view\&id=127\&Itemid=27 (acessado em 10/Fev/2011).

47. World Health Organization. World Health Report: now more than ever. Geneva: World Health Organization; 2008.

48. Dussault G. A health workforce strategy for Portugal. Cah Sociol Demogr Med 2007; 47:235-40.

49. World Health Organization. World Health Report 2000: health systems - improving performance. Geneva: World Health Organization; 2000.

50. Baker GR. Healthcare managers in the complex world of healthcare. Front Health Serv Manage 2002; 18:23-32.

Recebido em 12/Set/2012

Versão final reapresentada em 01/Jul/2013

Aprovado em 06/Ago/2013 